\title{
Trainers' Qualifications in Competence Based Education and Training Implementation and Acquisition of Employable Skills Among Visually Impaired Learners in TVET Institutions in Kenya
}

\author{
Priscillah Nduku Mutua $^{1 *} \quad$ Dr. David Mulwa ${ }^{2} \quad$ Dr. Richard Kimiti ${ }^{2}$ \\ 1.Post Graduate Student: Machakos University \\ 2.Lecturers: Machakos University
}

\begin{abstract}
The purpose of this study was to examine the extent to which trainers' qualifications in CBET implementation influence the acquisition of employable skills among visually impaired learners in TVET institutions in Kenya. The study applied a mixed methods research design. The study targeted 2 principals, 20 heads of departments, 70 trainers, 150 visually impaired learners and graduates of Machakos Technical Institute for the Blind and Sikri Technical Training Institute for Deaf-Blind, 2 Ministry of Education officials in charge of TVET, Curriculum Development Accreditation and Certification Council officials, 3 Ministry of Labour officials, 10 members of civil society groups and 5 managers of industries. A census of the principals and trainers was taken while purposive sampling was used to sample the rest of the respondents. Primary data was collected using questionnaires, interview schedules, focused group discussion guide and observation checklists. Quantitative data was analyzed using descriptive and inferential statistics while qualitative data was analyzed using content analysis. The study established a shortage of trainers in most departments within the institutes attributable to continuous increase in learners with special needs and multiple disabilities and the requirement for one trainer per learner at a given time for learners with visual impairments. It was also established that quite a large number of trainers in the TVET institutions were not adequately equipped to implement the CBET approach with a particular focus on the visually impaired learners (VILs). The study further noted that the acquisition of employable skills among VILs was positively and significantly influenced by trainers' qualifications in CBET implementation. The study concluded that trainers' qualifications had considerable impact of level of the acquisition of employable skills among VILs. Keywords: Competence based education and training, employable skills, trainers' qualifications, visually impaired learners.
\end{abstract}

DOI: $10.7176 / \mathrm{JEP} / 10-29-02$

Publication date:October $31^{\text {st }} 2019$

\subsection{INTRODUCTION}

Technical and Vocational Education and Training (TVET) systems play a pivotal role in the social and economic development of a country since it addresses pertinent issues related to unemployment, poverty and competitiveness in skills development (Kenya Policy Framework on Technical and Vocational Education and Training, 2012). Consequently, TVET Systems are continuously subjected to forces that drive changes in institutions, industry and the society. One such force is the need to have a competent workforce. In this regard, as outlined by Ferej, Kitainge and Ooko (2012), quality and relevance is a critical component of education and training worldwide. The concern being not so much about the value and importance of TVET, but how to ensure its relevance, responsiveness and value in an increasingly global economy (Law, 2007). In an effort to enhance this aspect of education and training, countries have embraced competence based education and training (CBET) as a strategy to prepare learners more effectively for the real workplaces. This is achieved by taking into account the industry requirements. This is in response to unique challenges and opportunities of TVET based on the needs of the changing economies and society (Anane, 2013). Goals of education indicate how TVET is integrated in determining solution of challenges associated with the development agenda of the country.

In Kenya, education goals as embodied in Vision 2030 emphasize enlarging learner's knowledge, experiences and imaginative understanding in addition to developing an awareness of moral values and capacity for life-long learning. Consequently, Kenya has embarked on reforms to strengthen TVET capacity as a basis to enable the country participate as a full partner in the world's fast growing, knowledge-based economy. This is evidenced by the national curriculum policy where among others, there is a deliberate effort to turn the Kenya education system into competence based education and training at all levels of education.

CBET is a program of study with clearly defined, concrete and measurable objectives of which every student participating in the program must have demonstrated mastery upon program completion (DeiBinger \& Hellwig, 2011). According to Kaaya (2012), CBET is the specification of knowledge and skill and the application of that knowledge and skill to the standard of performance expected in the workplace. Kufaine and Chitera (2013) state 
that the implementation of CBET by nations is geared towards the attainment and demonstration of skills to meet industry specified standards. Countries are therefore seeking to create an internationally competitive workforce by reforming their education and training systems.

In line with changing structures of work and economy globally, nations are seeking through CBET, to provide a more universal system of vocational education, encompassing both initial vocational preparations for school leavers and continuing training for the existing adult workforce. According to the Ministry of Planning (2010) in relation to Kenya's Vision 2030, the country intends to create a globally competitive and adaptive human resource base that can meet the requirements of a rapidly industrializing economy through CBET. An important approach to realize the Kenya Vision 2030 and the Big Four Agenda is through TVET based on close collaboration between industry and training institutions. In a similar vein, Kenya Vision 2030 has a special preference for the learners with special needs, which has not been properly translated to reality.

One of the most important features of CBET, as recognized by governments, is its orientation towards the world of work with the curriculum emphasizing the acquisition of employable skills. Despite these efforts, estimations are that $15 \%$ of TVET learners have disabilities with $7 \%$ of them being visually impaired. The main challenge for the learners with visual impairments is related to among others incompetent trainers given the special needs of these learners compared to sighted learners (Abban \& Quarshie, 2016). Muneja (2015) observes that trainers in most TVET institutions, trainers had limited understanding of the CBET. These trainers were happy in their teaching profession regardless of challenges faced when teaching following CBET curriculum. This challenge hinders them from adequately imparting quality skills and competencies to learners which leads to the unemployment of these learners upon graduating. Nonetheless, literature relating TVET trainers' qualifications in CBET implementation and acquisition of employable skills among is limited. This gap motivated the undertaking of this study.

\subsection{Statement of the Problem}

In Kenya, technical manpower is highly significant and there is a tremendous need towards improvement of its scope. Thus, TVET which is more practical and market-oriented remains as the solution to the issue of unemployment among visually impaired graduates, but hitherto, it is not parallel to its CBET curriculum. Other shortcomings influencing skills acquisition among visually impaired learners are poor instructional methods and strategies by trainers and use of outdated and unmodified training equipment as well as inadequate facilities. Upon graduating, the learners are exposed to technology shock in the job-market. It is patent that this problem escalates among learners with special needs more so the visually impaired. Thus, the incidence of inadequacy of learning facilities among learners with special needs was adverse, yet there were minimal attempts to eradicate it (Kenya National Survey on PWDs, 2016).

In addition, the numbers graduating with visual impairment had not been accepted in the society as individuals having the capacity to perform acquired skills. This was creating a biased imbalance, as more workforces were ignored due to disability. Furthermore, the employers had reservations in deploying people with visual impairment because they were alleged as burden in industry such that employers' trust was relatively low. In a similar vein, there was discontent among customers served by people with visual impairment since they are perceived as not competent (Palmer, 2017). In another reflection, visually impaired learners were capable of being self-employed; however, literature on this matter was scanty. Furthermore, literature to shed more light on matters related to adaptability of facilities applied in CBET implementation and employability skills acquired by the visually impaired learners was not comprehensive. It was upon this criticism that this research was built.

\subsection{Objective of the Study}

To examine the extent to which trainers' qualifications in CBET implementation influence the acquisition of employable skills among visually impaired learners in TVET institutions in Kenya.

\subsection{METHODOLOGY}

The study applied a mixed methods research design. The study targeted 2 principals, 20 heads of departments, 70 trainers, 150 visually impaired learners and graduates of Machakos Technical Institute for the Blind and Sikri Technical Training Institute for Deaf-Blind, 2 Ministry of Education officials in charge of TVET, Curriculum Development Accreditation and Certification Council officials, 3 Ministry of Labour officials, 10 members of civil society groups and 5 managers of industries. A census of the principals and trainers was taken while purposive sampling was used to sample the rest of the respondents. Primary data was collected using questionnaires, interview schedules, focused group discussion guide and observation checklists. Qualitative data was analyzed using content analysis while for the quantitative data, both descriptive and inferential analyses were undertaken with the aid of the statistical package for social sciences. Bivariate regression analysis was used generate regression coefficients, $t$ statistic and associated $p$ value that guided the testing of the stated hypothesis. 


\subsection{FINDINGS AND DISCUSSIONS}

\subsection{Trainers' Qualifications in CBET Implementation}

The study examined the extent to which trainers' qualifications in CBET implementation affected the acquisition of employable skills among visually impaired learners in TVET institutions in Kenya.

\subsubsection{Descriptive Analysis on Trainers' Qualifications in CBET Implementation}

The trainers responded to a number of statements presented that were related to trainers' qualifications in CBET implementation in their institutes. The findings are presented in Table 1.

\section{Table 1: Trainers' Qualifications in CBET Implementation}

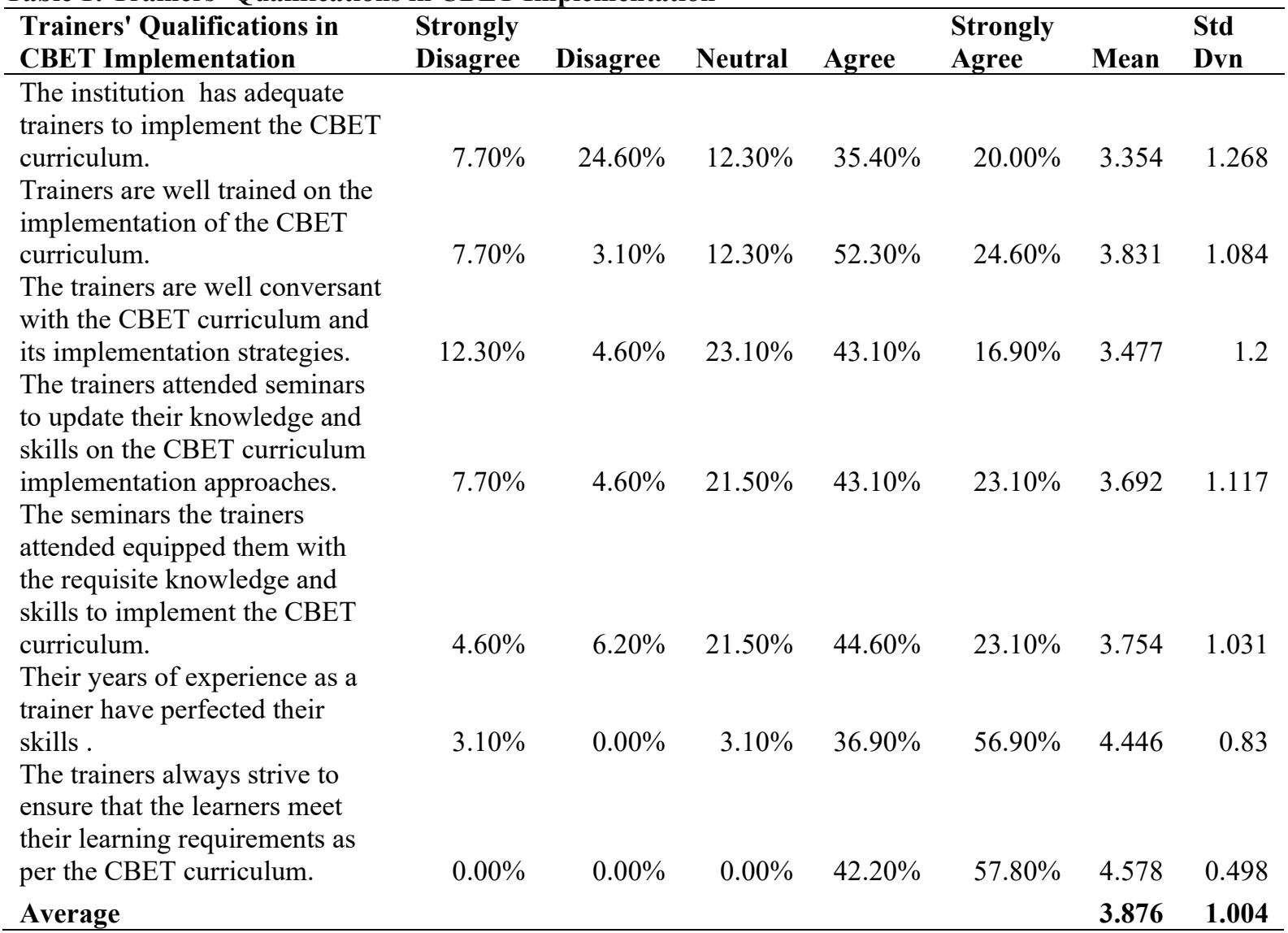

The findings showed that on average, the trainers had a neutral view regarding whether their institutions' had adequate trainers to implement the CBET curriculum as shown by $(M=3.354, S D=1.268)$ and whether the trainers were well conversant with the CBET curriculum and its implementation strategies given $(M=3.477, S D=1.200)$. The study also found that the trainers on average agreed that trainers were well trained on the implementation of the CBET curriculum $(M=3.830, S D=1.084)$ and that the trainers in their institutions attended seminars to update their knowledge and skills on the CBET curriculum implementation approaches as shown by $(M=3.692$, $S D=1.117)$

Similarly, the trainers on average agreed that the seminars the trainers attended equipped them with the requisite knowledge and skills to implement the CBET curriculum given $(M=3.754, S D=1.031)$ and that their years of experience as trainers had perfected their skills given $(M=4.446, S D=0.830)$. The findings further showed that the trainers strongly agreed that that the trainers always strived to ensure that the learners met their learning requirements as per the CBET curriculum as supported by $(M=4.578, S D=0.498)$. The study found that the highest mean of responses was associated with the statement "The trainers always strive to ensure that the learners meet their learning requirements as per the CBET curriculum" $(M=4.578, S D=0.498)$ while the lowest mean was attached to the statement "The institution has adequate trainers to implement the CBET curriculum" ( $M=3.354$, $S D=1.268)$.

Olabiyi, Adigun and Adenle (2008) underscores that the implementation of CBET in TVET institutions depends on the quality of the trainers' ability to effectively manipulate, operate, and use equipment, tools and materials to help learners understand the contents of the curriculum. Muneja (2015) also emphasizes that TVET trainers need to possess several attributes for effective teaching among them being able to apply learning principles to teaching and imparting critical thinking attributes to the learners which supported their knowledge acquisition processes. Further, Adebambo (2017) asserted that TVET principals and trainers should have a working knowledge 
on what CBET entailed in order to help learners prepare for the world of work. Capella (2011) on the other hand suggests that the trainers should go for refresher courses, in - service courses and capacity building workshops in order to be able to adequately prepare their learners.

\subsubsection{Trainers Comments regarding their Qualification in CBET Implementation}

The trainers were asked to indicate how their qualification and training as a trainers impacted the acquisition of employability skills among visually impaired learners. The findings as outlined in Table 2 revealed that $22(33.8 \%)$ of the trainers noted that they were adequately qualified and competent to teach effectively due to great experience obtained in teaching the visually impaired. This enabled them to impart the necessary skills to the learners. On the contrary, $27(41.5 \%)$ of the trainers noted that they were not fully qualified to teach visually impaired learners using the CBET approach and hence found it difficult to train learners with the visual impairments on CBET. The findings revealed that $39(60.0 \%)$ indicated that they needed refresher courses to teach the visually impaired learners on how to handle new technology and equipment used in the market place while $46(70.8 \%)$ indicated that they needed more special training on technical areas and to improve their professional skills and knowledge so that they can competently prepare their learners.

The findings implied that without the necessary qualifications and competencies, the trainers were not able to efficiently train their learners and more particularly technical and specialized fields which could hinder their participation in implementing the CBET approach. This was more exacerbated where the learners had special needs. The findings also implied that a large number of trainers in TVET institutions still required intense capacity development to be able to implement the CBET approach especially those handling the visually impaired learners. This had an implication on the adequacy of skills imparted on the learners as well as the level of difficulties faced when training these learners more so when imparting core competencies.

The findings of this study supported that of Kitainge (2017) who found that in order to ensure quality teaching on CBET, a high degree of competence and a sense of responsibility was required on the part of the trainers, emphasizing the necessity of both the pre-service and in-service training of the trainers. The findings also agreed with Muneja (2015) who observed that some TVET trainers had limited understanding of the CBET. According to Jeanne (2014), trainers are mostly employed based solely on possession of subject knowledge after excelling in their university degree, even though lacking pedagogical and technical skills. Hence, the responsibility was bestowed to the employer to offer them short term on the job training on pedagogy which habitually did not yield the expected impact as trainers were already influenced by the long time knowledge that was based on the system in their prior education systems.

Table 2: Trainers Comments regarding their Qualification in CBET Implementation

\begin{tabular}{lcc}
\hline Comments regarding their Qualification in CBET Implementation & Frequency & Percent \\
\hline $\begin{array}{l}\text { Need refresher courses to teach visually impaired learners on how to handle } \\
\text { new technology and equipment used in the market place }\end{array}$ & 39 & 60.0 \\
$\begin{array}{l}\text { Need for more special training on technical areas and to improve skills and } \\
\text { knowledge }\end{array}$ & 46 & 70.8 \\
$\begin{array}{l}\text { Not fully qualified to teach visually impaired learners in regards to CBET } \\
\text { Adequately qualified and competent to teach effectively due to great experience } \\
\text { in teaching the visually impaired }\end{array}$ & 27 & 41.5 \\
\hline
\end{tabular}

\subsubsection{Graduate's Comments on Trainers' Knowledge in Imparting Skills using the CBET Approach}

The comments of the visually impaired graduates pertaining to how knowledgeable their trainers were in imparting skills to them using the CBET approach were also sought. From the responses given, it emerged that the graduates felt that their trainers were quite knowledgeable in imparting skills to them using this approach though much needed to be done to enhance the capacity of these trainers in training the learners with visual impairments. According to one of the graduates,

"The trainers had adequate knowledge in using this approach but some did not know how to use braille.

Trainers need to be trained on braille for more efficiency."

Another graduate added that,

"They are quite knowledgeable but refresher courses and other capacity building programs would be necessary to some especially for practical lessons."

Another graduate concurred that,

"They are well conversant with the training though there is need for refresher courses at time."

While noting the importance of the trainers to be more approachable, one of the graduates indicated that,

"Trainers were okay. Taught us important skills, teachers were approachable and ready to listen.

However, problems would emerge when it came to consultations in much technical areas."

Another graduate indicated that

"Some trainers were hot tempered so it affected training sometimes. Some did not know how to use braille, at least they should be knowledgeable of braille, there were no books, they gave notes so much." 
These findings underscore the need for constant capacity development for the trainers especially on specific areas that touch on particular needs of those with special needs such as the use of braille in this case as well as the cultivation of people skills among the trainers so that they handle the learners with care. This would minimize negative feelings among the learners based on the treatment they received from their trainers which of not handle could lead to resentment adversely affecting their learning. However, the MOE official during the interview indicated that the trainers in TVET institutions were competent to teach CBET to visually impaired learners. They further added that the trainers often attended seminars/workshops once per year. The findings were in line with the study by Capella (2011) which suggested that the trainers in TVET institutions should go for refresher courses, in-service courses and capacity building workshops on a continuous basis.

\subsubsection{Staffing of Departments with Trainers to Implement CBET}

From the focus group discussion held with the HODs, it emerged that $6(60.0 \%)$ of the HODs noted that their departments were not fully staffed and 4(40\%) of HODs of the other departments were adequately staffed. It was highlighted that even though the ratio of learner trainer was supposed to be 1:5 as per the SNE policy 2018, this was not the case in the institutes. The main explanation given was the increase of learners with special needs and multiple disabilities and the requirement of the visually impaired to have a trainer per learner at a given time. It was also pointed out that most of the trainers were trained in seminars which had not adequately equipped them. The findings implied that the visually impaired learners in TVET institutions were not adequately catered for due to shortage of trainers and that the provisions of the Special Needs Education Policy of 2018 were not strictly observed in the training of the visually impaired in these institutions. The shortage of trainers or having trainers that were not fully competent compromised the quality of training. This had an adverse impact on the acquisition of employable skills among the learners. This was aggravated where some trainers in some departments had acquired only internal certificates in Special Needs Education particularly for the visually impaired or relied on information given during seminars that took place once in a while since they could not sufficiently train learners. Part of these findings supported the sentiments by Jeanne (2014) that short term on the job training on pedagogy habitually did not yield the expected impact as trainers were already influenced by the long time knowledge that was based on the system in their prior education systems.

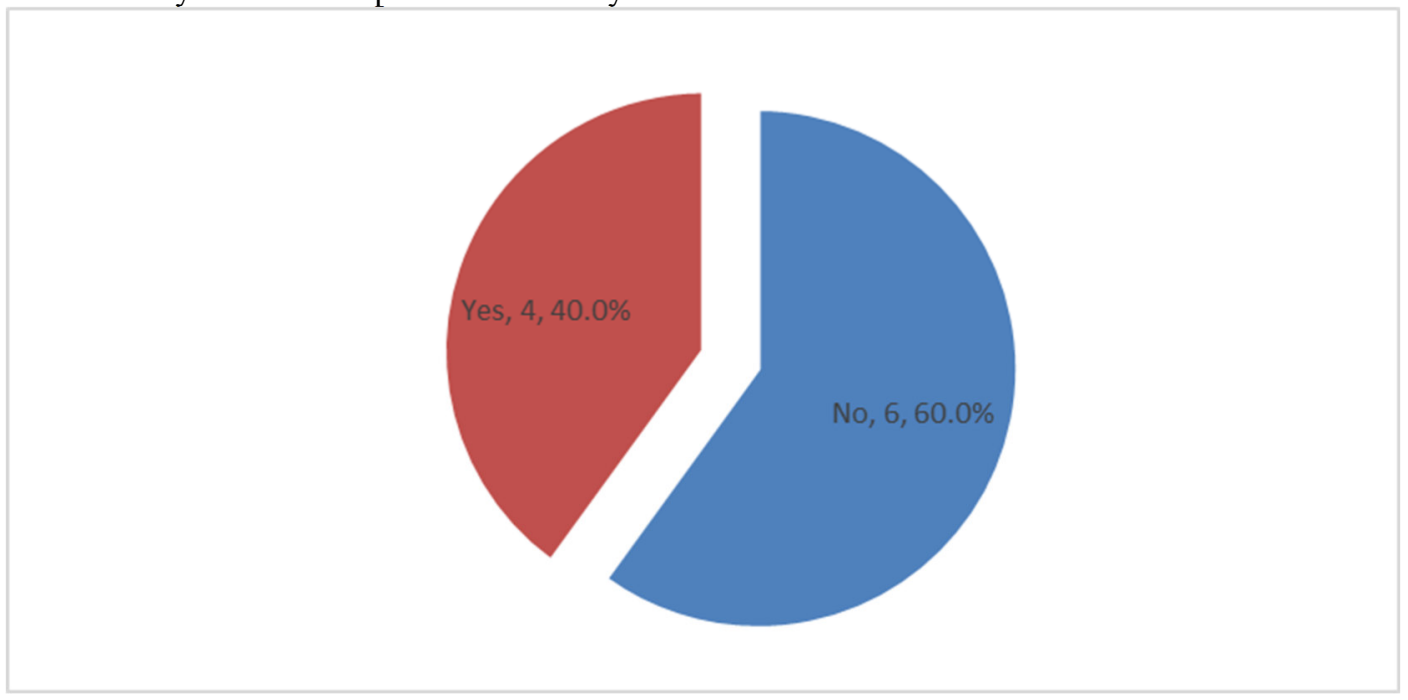

Figure 1: Level of Staffing of Departments with Trainers to Implement
3.1.5 Staffing of Different Departments with Trainers Equipped to Implement CBET

The HODs were also asked to assess the extent to which the trainers in their departments were equipped to implement the CBET mode of training. Half of the HODs, $5(50.0 \%)$ indicated that their trainers were not adequately equipped. Some of the comments given were that;

"Some of the trainers are not well trained. They require further training". HOD 1

In support of this view, another HOD noted that,

"Our trainers are fairly equipped given the need for continuous adaptability of their training to the new curriculum demands which is an ongoing process." HOD 2

It was also argued by one of the HODs that their trainers lacked the necessary resources needed to adequately enable them to implement the CBET approach. In explaining, they noted that,

"Some departments lack enough training materials and other resources needed especially for practical lessons which is a challenge for trainers.” HOD 6

The findings implied that some departments were more staffed with well-equipped trainers than others which resulted to disparities in the level of competency of graduates from different technical areas. On the other side, those who felt that their departments had trainers who were adequately equipped to implement the CBET approach 
indicated that every staff in their departments had acquired trainer of trainer courses and also trained in both special needs education (SNE) and technical skills.

\subsubsection{Acquisition of Employable Skills among the Visually Impaired Learners}

The trainers were asked to give their assessment of the employability skills acquired by their visually impaired graduates and the findings are summarized in Table 3. The study found that on average, the trainers agreed that the visually impaired graduates from their institutions had acquired basic skills (reading, writing, listening, speaking, mathematics) given $(M=4.185, S D=0.950)$. The trainers also on average agreed that the graduates had acquired thinking skills (creative thinking, effective decision making, problem solving, reasoning skills, ability to learn) $(M=4.138, S D=0.583)$, personal qualities (taking responsibility for actions, goal oriented, friendly, open, honest, meeting customer demands) $(M=4.062, S D=0.659)$ and integrity (honest, sound moral character and values) $(M=4.123, S D=0.740)$.

The findings further showed that on average, the trainers agreed the visually impaired graduates had acquired Resource management skills (identifying, organizing, planning, and allocating resources; prioritizing; time and project management) $(M=3.831, S D=0.876)$, that they had acquired interpersonal skills (working well with others as a team, openness to diversity, excellent customer service skills) $(M=4.154, S D=0.734)$ as well as systems management skills (understand and effectively work with social, organizational, and technological systems) $(M=3.754, S D=0.867)$. Similarly, the trainers agreed that their VI graduates had acquired technology use skills (working with computers and other technology, selecting right tools, equipment, hardware, and software for a job, and application of knowledge to tasks) $(M=3.538, S D=0.867)$, and that they had acquired adaptability skills (ability to adapt to changing work environments) as shown by $(M=3.938, S D=0.768)$. The trainers were on average in agreement that their graduates had acquired work ethics skills (performing the assigned duties according to the laid down regulation, ability to design/make needed customer items within the set time) $(M=4.185, S D=0.864)$ and also professionalism (acting in a responsible manner, maturity, self- confidence) $(M=4.169, S D=1.009)$.

According to Ayonmike, Okwelle and Okeke (2014), CBET can be viewed as a way of approaching (vocational) training that puts much emphasis on skills acquisition and knowledge. The findings supported the study by Kufaine and Chitera (2013) which found that CBET approach helped the learners to acquire skills that were necessary for the industry. The findings implied that CBET curriculum allowed the government to empower its people with the needed knowledge and skills, attitudes and values which enabled them to be empowered for both individual and general development in line with Ayonmike, Okwelle and Okeke (2014). In his study, Chatsworth (2012) outlines twelve important issues of employability such as problem solving, leadership skills, analytical thinking skills, organizational and cooperative building, communication skills, competence, commerciality, work achievement, flexibility, customer focus and developing skills and training people; these outline helped to bridge the need of graduates to enhanced soft and technical skills characteristics. 
Table 3: Employability Skills Acquired by Visually Impaired Learners

\section{Employability Skills Acquired}

by Visually Impaired

Learners

Basic skills (reading, writing,

listening, speaking,

mathematics)

Thinking skills (creative

$3.10 \%$

Strongly

Disagree Neutral Agree

Strongly

Std

Agree

Mean

Dvn

thinking, effective decision

making, problem solving,

reasoning skills, ability to learn)

Personal qualities (taking

responsibility for actions, goal

oriented, friendly, open, honest, meeting customer demands).

Integrity (honest, sound moral

character and values)

Resource management

(identifying, organizing,

planning, and allocating

resources; prioritizing; time and

project management)

$3.10 \%$

$4.60 \% \quad 46.20 \%$

$41.50 \%$

4.185

0.950

Interpersonal skills (working

well with others as a team,

openness to diversity, excellent

customer service skills)

$0.00 \%$

$0.00 \%$

$10.80 \% \quad 64.60 \%$

$24.60 \%$

4.138

0.583

Systems management

(understand and effectively

work with social,

organizational, and

technological systems)

Technology use (working with

computers and other

technology, selecting right

tools, equipment, hardware, and

software for a job, and

application of knowledge to

tasks)

$0.00 \%$

$3.10 \%$

$9.20 \%$

$66.20 \%$

$21.50 \% \quad 4.062$

0.659

$3.10 \%$

$0.00 \%$

$3.10 \%$

$69.20 \%$

$24.60 \% \quad 4.123$

0.740

Adaptability (ability to adapt to changing work environments)

Work ethics (performing the assigned duties according to the laid down regulation, ability to design/make needed customer items within the set time) Professionalism (acting in a responsible manner, maturity, self- confidence)

$0.00 \%$

$7.70 \%$

$24.60 \%$

$44.60 \%$

$23.10 \% \quad 3.831$

0.876

$3.10 \%$

$0.00 \%$

$1.50 \%$

$69.20 \%$

$26.20 \%$

4.154

0.734

$3.10 \%$

$1.50 \%$

$29.20 \%$

$49.20 \%$

$16.90 \% \quad 3.754$

0.867

Average

\begin{tabular}{lllllll}
$0.00 \%$ & $15.40 \%$ & $24.60 \%$ & $50.80 \%$ & $9.20 \%$ & 3.538 & 0.867 \\
$0.00 \%$ & $3.10 \%$ & $23.10 \%$ & $50.80 \%$ & $23.10 \%$ & 3.938 & 0.768 \\
& & & & & & \\
& & & & & & \\
$3.10 \%$ & $0.00 \%$ & $10.80 \%$ & $47.70 \%$ & $38.50 \%$ & 4.185 & 0.864 \\
& & & & & & \\
$4.60 \%$ & $4.60 \%$ & $1.50 \%$ & $47.70 \%$ & $41.50 \%$ & 4.169 & 1.009 \\
& & & & & $\mathbf{4 . 0 0 7}$ & $\mathbf{0 . 8 1 1}$ \\
\hline
\end{tabular}

3.2 Correlation Between Trainers' Qualifications in CBET and Acquisition of Employability Skills among Visually Impaired Learners

Correlation analysis was also undertaken to determine whether there was significant association between trainers' qualifications in CBET and the acquisition of employability skills among visually impaired learners in TVET institutions in Kenya. The study found a strong, positive and significant correlation between trainers' competencies in CBET and acquisition of employability skills among visually impaired learners in these institutions given $(r=0.742, p=0.000, p<0.05)$. The findings implied that trainers' qualifications in CBET and acquisition of employable skills among these learners changed in the same direction. The findings of this study agreed with that 
of Rapp and Rapp (2012) who found that trainers training was positively and significantly related to the level of support provided to deaf-blind learners indicating that trainers ought to be well trained and experienced which ensured that they were well informed on the needs of multisensory impairment (MSI) learners.

Table 4: Correlation Between Trainers' Qualifications in CBET and Acquisition of Employability Skills among VILs

\begin{tabular}{lll}
\hline & Acquisition of & Trainers' \\
& Employability Skills & Competencies in \\
& among VILs & CBET \\
\hline
\end{tabular}

Acquisition of Employability

Skills among VILs

Trainers' Competencies in CBET

$$
\begin{aligned}
& \text { Pearson Correlation } \\
& \text { Sig. (2-tailed) } \\
& \text { N } \\
& \text { Pearson Correlation } \\
& \text { Sig. (2-tailed) } \\
& \text { N }
\end{aligned}
$$

** Correlation is significant at the 0.01 level (2-tailed).

\section{1}

$.742 * *$

1

0.000

65
65

\subsection{Regression Analysis between Trainers' Qualifications in CBET and Acquisition of Employability Skills among Visually Impaired Learners}

Regression analysis was carried out to establish the relationship that existed between trainers' qualifications in CBET and acquisition of employability skills among visually impaired learners in TVET institutions in Kenya. This enabled the researcher to quantify the effect of trainers' competencies in CBET on the acquisition of employable skills among these learners. The following null hypothesis was tested;

Ho1: Trainers' qualifications in CBET do not significantly influence the acquisition of employable skills among visually impaired learners in TVET institutions in Kenya.

\subsubsection{Model Summary}

The model summary results presented in Table 5 showed that trainers' qualifications in CBET explained a considerable proportion of the variation in the acquisition of employable skills among visually impaired learners in TVET institutions. This is supported by the R square of 0.551 which meant that $55.1 \%$ of the changes in the acquisition of employable skills among visually impaired learners in these institutions was attributed to changes in trainers' competencies in CBET. The rest of the variation in the acquisition of employable skills among these learners, $44.9 \%$, were attributed to other factors not considered in this model. The findings meant that trainers' qualifications in CBET was a significant variable in explaining the acquisition of employable skills among these learners in TVET institutions in Kenya.

Table 5: Model Summary for Trainers' Competencies in CBET

\begin{tabular}{lcccc}
\hline Model & R & R Square & Adjusted R Square & Std. Error of the Estimate \\
\hline 1 & $.742 \mathrm{a}$ & 0.551 & 0.544 & 0.367854 \\
a Predictors: (Constant) & Trainers' qualifications in CBET & &
\end{tabular}

\subsubsection{Model Fitness}

The model fitness results presented in Table 6 showed that the model used to show the link between trainers'

\begin{tabular}{|c|c|c|c|c|c|c|}
\hline Model & 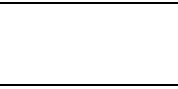 & $\begin{array}{c}\text { Sum of } \\
\text { Squares }\end{array}$ & df & $\begin{array}{c}\text { Mean } \\
\text { Square }\end{array}$ & $\mathbf{F}$ & Sig. \\
\hline 1 & Regression & 10.472 & 1 & 10.472 & 77.388 & $.000 \mathrm{~b}$ \\
\hline & Residual & 8.525 & 63 & 0.135 & & \\
\hline & Total & 18.997 & 64 & & & \\
\hline \multirow{2}{*}{\multicolumn{7}{|c|}{$\begin{array}{l}\text { a Dependent Variable: Acquisition of employable skills among } \\
\text { visually impaired learners }\end{array}$}} \\
\hline & & & & & & b Predictors: (Constant), Trainers' qualifications in CBET \\
\hline
\end{tabular}
qualifications in CBET and acquisition of employable skills among the visually impaired learners in TVET institutions was significant given $F(1,63)=77.388, p=.000<0.05$. The findings also showed that trainers' competencies in CBET was a significant predictor of the acquisition of employable skills among the visually impaired learners in these institutions.

Table 6: Model Fitness Results 


\subsubsection{Regression Coefficient for Trainers' Competencies in CBET}

The regression coefficient output displayed in Table 7 showed that the acquisition of employable skills among visually impaired learners in TVET institutions was positively and significantly affected by trainers' competencies in CBET given $\beta=0.881, t=8.797, p=.000, p<0.05$. The findings implied that a unit increase in trainers' competencies in CBET would result to increased acquisition of employable skills among the visually impaired learners in TVET institutions by 0.881 units holding all other factors constant. These findings led to the rejection of the null hypothesis and an inference made that the acquisition of employable skills among the visually impaired learners in TVET institutions in Kenya was significantly affected by trainers' competencies in CBET.

The findings were in agreement with that of Khatib (2017) which showed that there was a marked difference in the quality and quantity of competencies acquired by visually impaired and blind learners due to the characteristics of the trainers. The study underlined the need for trainers to have special education competencybased services. The findings also agreed with that of Dasmani (2011) who found that TVET teachers ought to undergo regular industrial training which ensured that they did not lag behind in new knowledge on technological advancement in industries. This would ensure quality of training which helped students to acquire employable skills. The findings further supported that of Udofia, et.al. (2012) which revealed that there was a significant relationship between teacher quality with the acquisition of employable skills by students in TVET institutions. The study explained that since most of the teachers were the students' role models, they needed to have adequate knowledge on labour markets needs which made it easier for the teachers to transfer the employable skills.

The following model was fitted;

Acquisition of Employability Skills among Visually Impaired Learners in TVET Institutions in Kenya $=0.526+$ 0.881 Trainers' Qualifications in CBET

Table 7: Regression Coefficient for Trainers' Competencies in CBET

\begin{tabular}{|c|c|c|c|c|c|c|}
\hline \multirow{2}{*}{\multicolumn{2}{|c|}{ Model }} & \multicolumn{2}{|c|}{$\begin{array}{l}\text { Unstandardized } \\
\text { Coefficients }\end{array}$} & \multirow{2}{*}{$\begin{array}{c}\begin{array}{c}\text { Standardized } \\
\text { Coefficients }\end{array} \\
\text { Beta } \\
\end{array}$} & \multirow[t]{2}{*}{ t } & \multirow[t]{2}{*}{ Sig. } \\
\hline & & B & Std. Error & & & \\
\hline 1 & (Constant) & 0.526 & 0.398 & & 1.321 & 0.191 \\
\hline a Depend & $\begin{array}{l}\text { Trainers' Competencies in } \\
\text { CBET } \\
\text { nt Variable: Acquisition of }\end{array}$ & $\begin{array}{c}0.881 \\
\text { able ski }\end{array}$ & $\begin{array}{c}0.100 \\
\text { among visua }\end{array}$ & $\begin{array}{c}0.742 \\
\text { mpaired learner }\end{array}$ & 8.797 & 0.000 \\
\hline
\end{tabular}

\subsection{CONCLUSIONS}

The study concluded that the institutes were not sufficiently staffed with trainers who could adequately train the visually impaired learners. The study concluded that there was disparity in staffing of various departments in the institutes and that the highly technical areas of specialization suffered the major shortages. The study also concluded that most of the trainers in these institutes were not adequately equipped to implement the CBET approach of training when it came to learners with visual impairments. The study further concluded that the trainer's qualification in CBET significantly affected the level of acquisition of employable skills among the visually impaired learners in TVET institutions.

\section{REFERENCES}

Abban, C., \& Quarshie, J. (2016). Integrated skills training for self-employment: The case of Ghana. In Grierson, J. P. \& Mckenzie I. (Eds): Training for self-employment through vocational training institutions. Turin, Italy: ILO International Training Centre.

Adebambo, K. A. (Ed.). (2017). Vocational and technical education and training. Ibadan: Gabesther Educational Publishers.

Anane, C.A. (2013). Competency based training: Quality delivery for technical and vocational education and training (TVET) institutions. Educational Research International, 2(2), 117- 127.

Brandt, B. L., Farmer Jr, J. A., \& Buckmaster, A. (1993). Cognitive apprenticeship approach to helping adults learn. New Directions for Adult and Continuing Education, 1993(59), 69-78.

Capella, M. (2011). Predicting earnings of vocational rehabilitation clients with visual impairments. Journal of Rehabilitation, 67(4), 43-47.

Cole, A. (2017). A Thousand Roses: Teacher Beliefs and Perceptions of Practice (Doctoral dissertation, McGill University Libraries).

Dasmani, A. (2011). Challenges facing Technical Institute graduates in practical skill acquisition in the Upper East Region of Ghana. Asia-Pacific. Journal, 12(2), 67-77.

Deißinger, T. \& Hellwig, S. (2011). Structures and functions of competency-based education and training (CBET): Development, 14(1), 54-64.

Dreyfus \& Dreyfus. (1986). A five stage model of the mental activities involved in directed skill acquisition. Operations Research Centre: California. 
Dzigbede, F. K. K. (2009). Challenges in the administration of technical Vocational education and training in the Ghana Education Service (Doctoral dissertation, University of Cape Coast).

Engestrom, Y. (1999). Innovative learning in work teams: Analyzing cycles of knowledge creation in practice. Perspectives on Activity Theory, 377, 404.

Ferej, A., Kitainge, K., \& Ooko, Z. (2012). Reform of TVET teacher education in Kenya: Overcoming the challenges of quality and relevance. Triennale on Education and Training in Africa, 12-17.

Jeanne, N. (2014). National certification initiative for employment support professionals: Promoting quality integrated employment services. Bowling Green State University. USA.

Kaaya, P.B. (2012). The importance of Competency Based Education and Training (CBET) on industrial performance in Tanzania. Paper Presented at the TVET Institutions and Industries Collaborations Conference Program, 12th October, 2012, Arusha Tanzania.

Khatib, M. R. (2017). Competencies needed for the teachers of visually impaired and blind learners in Al Balqaa province area schools. Turkish International Journal of Special Education and Guidance \& Counselling (TIJSEG) ISSN: 1300-7432, 6(1).

Kingombe, C. (2012). Lessons for developing countries from experience with technical and vocational education and training. Economic Challenges and Policy Issues in Early Twenty-First-Century Sierra Leone, 278-365.

Kitainge, K. (2017). Reforming education and training? Lessons from development of vocational Education and training in Kenya. Australian Journal of Adult Learning, 44(1), 44-61.

Kufaine, N. \& Chitera, N. (2013). Competency based education and training in technical education problems and perspectives. International Journal of Vocational and Technical Education, 5(3),37-41.

Ministry for State for planning, N. D. A. V. 2. (2010). Kenya vision 2030. Nairobi: Ministry of State for Planning, National Development and vision 2030

Muneja, M. S. (2015). Secondary school teachers' implementation of the competency-based curriculum in the Arusha Region, Tanzania. University of South Africa.

Ngure, S.W. (2013). Stakeholders' perceptions of technical, vocational education and training: the case of Kenyan micro and small enterprises in the motor vehicle service and repair industry. Unpublished MA thesis. Edith Cowan University.

Olabiyi, O. S., Adigun, E. O. \& Adenle, S.O. (2008). Assessment of the adequacy of training facilities used for vocational and technical education in colleges of education in South West Nigeria. African Journal for the Study of Educational Issues: 4 (3), 44-52.

Rowe, M. M. (2007). An Exploration of the Voices of Learners: The Learning Experience for Teachers and Students at the Vocational Training Development Institute (VTDI), Jamaica. The University of Manchester (United Kingdom).

Tarno E., Simiyu J., Kitainge K., and Rono A. (2017). Emerging Trends and Challenges in TVET in Sub-Saharan Africa. Rift Valley Technical Training Institute.

Terblanche, T. E. (2017). Technical and vocational education and training (TVET) colleges in South Africa: A framework for leading curriculum change (Doctoral dissertation, Stellenbosch: Stellenbosch University).

Udofia, A. E, Ekpo, A. B., Nsa, E. O., \&Akpan, E. O. (2012). Instructional variables and students' acquisition of employable skills in vocational education in Nigerian technical colleges. Scholarly Journal of Education, 1(2), 13-19.

Zelloth, H. (2014). Technical and vocational education and training (TVET) and career guidance: The interface. In Handbook of Career Development (pp. 271-290). Springer, New York, NY. 